\title{
The Present Situation of Empirical Accounting Research in China and Its Gap with Foreign Countries
}

\author{
Wei-Hua ZHANG \\ Zhejiang Yuexiu Foreign Languages College Shaoxing City, Zhejiang, China \\ E-mail: zwh_601@126.com
}

Keywords: Research method, Empirical research, Empirical accounting.

\begin{abstract}
An empirical study of accounting have already entered China for more than 20 years, but the real substantive research is the recent ten years, and in the process of empirical accounting in different stages have different views. This article through to 2006 to 2016 this period of empirical accounting paper retrieval analysis, change and development, the number of changes through the research and use of indicators analyzed one by one, and will study comparing with Western empirical accounting in China, analysis of the differences and reasons of difference.
\end{abstract}

\section{The Change of Positive Accounting in China from 2006 to 2016}

Study on the empirical accounting although in late 80s by the introduction of some scholars, but because of the lack of conditions at the time, and by 90s it has made some substantial progress of the study, so the early 90s, accounting research in our country is very scarce empirical application. After ten years of development, China's empirical accounting research in the field of a number of young and middle-aged accounting scholars efforts, has shown a prosperous scene. At the same time, Chinese scholars for empirical research methods in accounting field is radically changed, is no longer a single accounting standard research but to learn from the West will study accounting empirical research and normative accounting combination of research, after ten years of development of China's accounting scholars for the level of understanding of empirical accounting research is also growing.

With the deepening of the empirical accounting research and the substantial application of positive accounting methods, the accounting profession has come to realize that the relationship between normative and empirical accounting should be complementary. The empirical research in accounting research and accounting results have great relevance in the analysis and put forward to the results of the regression on the assumption of the normative accounting theory lays a theoretical foundation for the full empirical accounting research, at the same time the empirical research on accounting theory and its main feature is the process of researching and natural science of accounting research through the combination of empirical data to test the hypothesis, and the combination of qualitative analysis and quantitative analysis, and thus regulate the inadequacies of the study of accounting theory and methods can be used to carry out empirical research in accounting for. Due to the assumptions from theory to process specific assumptions are qualitative analysis and logical analysis, quantitative analysis method and the advantage of the process to test the hypothesis. The actual data of the accuracy in the research on the results of empirical research to the high number of. Therefore, researchers in the field of accounting in the process of scientific research, only the two kinds of accounting research methods can be used in combination to ensure the quality of scientific research, high efficiency. [1]

\section{The Main Results of Empirical Accounting Research in China from 2006 to 2016}

The empirical accounting research in China from the last century the late 90s have made substantial progress, so the number of the ten years from 2006 to 2016 China's empirical accounting research has undergone great changes, from the research results before and after the scanty to the rich. This paper will be on 2006 to search through the empirical research in accounting literature between 2016 and 
analyze the research results of empirical accounting research in our country is mainly reflected in the following aspects: accounting information, accounting policy choice, and accounting standards, financial problem, cash flow, earnings management and audit issues, this article is also it is analyzed from the following aspects.

\section{A Summary of the Empirical Study on the Content of Empirical Accounting Research from 2006 to 2016}

From 2006 to 2016, the classification of empirical accounting research in china. It can be seen that in the past ten years, the number of papers in China has increased from 0 in 2006 to about 86 in 2016. The increase in the number of empirical papers on behalf of the accounting profession in China is more and more focused on empirical accounting research. However, it is still a small part of the total number of articles published in China from 86 figures, which shows that the accounting profession in China should strengthen the research on positive accounting. This is from a number of ways, from published the contents of the article said, rarely involved between 1996 to 1999, in 2006 to 2016, especially in 2007 and 2016 to basically the above aspects are involved, these figures can explain the empirical accounting research field of our country gradually broadening. In these studies, the number of empirical studies on financial issues has been the largest, in these articles are mainly for the study of financial crisis early warning and financial risk of these two issues. The number of research articles on audit issues the next is section more than and 2, which is the main problem of audit audit opinions and audit fees in two aspects. Secondly, accounting policy and choice.

\section{The Main Content of Empirical Accounting Research and the Summary of its Index Variables}

In the empirical analysis and hypothesis testing methods of empirical accounting research articles usually need to use variables, so the research content in the several main aspects of this paper are summarized and the index variables using these aspects in the process of statistics and analysis, the main purpose of doing so is to the empirical accounting research in China in setting up the index variable rules. [2]

\section{The Main Research Contents and Indicators of Accounting Information in Empirical Accounting Research}

Can be developed through the literature research summary process, in the analysis of the relevant research of accounting information in the article, the research of accounting information are the main stock price and accounting information, the social responsibility accounting information, environmental accounting information in these aspects. Inventory turnover, accounts receivable turnover, earnings per share, shareholder return ratio, rolling ratio of net assets per share and sales profit rate index is used in these variables in the empirical accounting research accounting information article basically used. In addition to the above mentioned those indicators there are many scholars also according to their contents and emphases, the use of the index of their research as required by the total rate of return on assets, return on net assets, the main business profit rate, net assets per share.

\section{The Main Research Contents and Indicators of Accounting Policy and Choice in Empirical Accounting Research}

In the study of accounting and selection, this paper mainly focuses on two aspects: one is the choice of accounting policies and the other is the change of dividend policy. The operating cash flow per share, the natural logarithm of total assets, the rate of return on net assets, the ratio of assets to liabilities are all involved in the accounting policy choice in empirical accounting research. While the scale of assets, earnings per share and cash dividend per share, net operating cash flow, non-tradable shares ratio, rate of return on net assets, the ratio of the traded shares of ownership concentration, the proportion of state-owned shares, the total share capital, assets and liabilities rate of these indicators is the choice of dividend policy aspect research literature contained in the index. 


\section{The Main Research Contents and Indicators of Accounting Standards in Empirical Accounting Research}

In our country's accounting standards research literature is mainly about the accounting standards and the accounting standards of our country and foreign accounting standards of the two types of comparative study. In the process of analysis of literature on accounting standards in part can understand this part of the literature often used indicators, the consolidated profit and loss difference and income and cost difference, the allowance for bad debts and inventory difference differences, income differences, joint venture capital expenditure difference amortization difference, investment loss difference index. The indicators used in the comparative study with foreign accounting standards in the article are: employee award, welfare fund, public welfare fund, exchange rate, financial return, cost of capital, deferred tax, purchase interest, debt restructuring, the annual cost of preparation and adjustment, sale and transfer of business Affiliated Companies, revaluation of fixed assets appreciation, received donations of fixed assets, fixed assets depreciation difference, the disposal of fixed assets and fixed assets confirmation, revenue recognition benchmark, Affiliated Companies merger difference, adjustment of minority shareholders profit, affiliate transaction unrealized profit, deferred income tax adjustments, amortization, identification and cost adjustment, the equity method of accounting differences, non-monetary transactions, investment income and equity investment difference index.

\section{The Main Research Contents and Indicators of Cash Flow in Empirical Accounting Research}

In the study of the empirical accounting cash flow, the main contents include the research of the information content, the influence factors, the value relevance and the cash flow. Through the empirical accounting on the cash flow of the statistics from 2006 to 2016 in the article, because each research emphases are different, it is difficult to find a consistent index, but the three indexes of operating cash flow per share, earnings per share, cash flow in the statistical literature have appeared, in addition to the three there are some index number is not very high index, the main indicators of asset profit rate, the difference between the net profit cash content, profit and net operating cash flow rate, the rate of return on net assets, stock price, dividend per share, asset liability ratio etc..

\section{The Main Research Contents and Indicators of Earnings Management in Empirical Accounting Research}

In this part of the development of the literature retrieval set the main indexes are: the sizes of assets, the main business income, increase the amount of accounts receivable, operating profit / total assets, net operating cash flow / total assets, net assets yield, total profits accrued asset liability ratio.

\section{The Main Research Contents and Indicators of the Audit Problems in Empirical Accounting Research}

At present, the main research direction of the empirical research literature on audit is the research of the influence factors of audit opinion and the influencing factors of audit fees in these two parts. Through the analysis of the article that contains the retrieval and audit opinion articles related to the main indexes are: the total assets turnover rate, the rate of return on net assets, the main business profit rate, asset liability ratio, expected future earnings, earnings per share, auditor size, firm size, cash ratio, and liquidity ratio. In the study of the project set the control variables are the following, is not the big ten firms, firms have not changed, the audit opinion of the previous year, the last year's profit and loss situation and whether there is a lack of motivation. Involved in part of the research on audit fees in the literature the main indicators, asset size, audit fees, asset liability ratio, inventory / total assets, accounts receivable / total assets, accounts receivable and inventory number / total assets, net assets yield, number of statements, consolidated into the company independent directors. And in this part of the control variables are, the company's location is not the ten big firms, listed companies have not been issued a non-standard and annual report there is no loss. 


\section{The Main Research Contents and Indicators of Financial Problems in Empirical Accounting Research}

Through the classification of the research content in the literature, we can know that the research of financial problems is mainly based on the research of financial crisis and financial distress prediction. The evaluation index system of financial performance is an important factor affecting the index of this part of the study, so when the scholars in the index mainly consider the following aspects of enterprise financial situation, development ability, operation ability, profit ability, risk level, short-term solvency, debt repayment ability K. Then determine the final result to influence or regression model indicators: rate of return on net assets, assets turnover, the main business profit rate, equity / total assets, working capital / total assets, retained earnings / total assets, EBIT, total assets growth rate of total assets, the main business the growth rate of income growth rate, accounts receivable, asset liability ratio etc.. At the same time that the operating activities net cash flow / current liabilities, net operating cash flow / main business income, net cash flow / total debt, debt guarantee rate analysis of cash flow impact on the financial status of the main index. [3]

Through the use of China from 2006 to 2016 in the empirical accounting literature content index of the analysis, can be found from the core indicators of China's scholars in the study of the content setting is basically the same, but there are differences of the index set, mainly study according to their different research purpose while the corresponding increase in the other required index.

\section{An Analysis of the Development of Empirical Accounting Research Methods in China from 2006 to 2016}

The scope of empirical accounting research in our country has been continuously expanded after decades of efforts, mainly reflected in the research methods tend to fine and complex. The empirical research methods include the broad and narrow aspects. First of all, the narrow sense of the empirical research method simply refers to the study of archives, and archival research can be divided into three types: observation, empirical analysis and hypothesis testing. We usually say that the positive accounting research in the literal interpretation of the meaning of empirical accounting research, but in fact it is a branch of archival research. Secondly, the general empirical accounting research methods include five aspects, namely, archival research, survey research, field research, case study and laboratory experiment. In this paper, the empirical accounting articles from 2006 to the year of the year of the year of the year of 2016 are all the articles of the general concept.

\section{Statistics of the Research Methods used in Empirical Accounting Research in China from 2006 to 2016}

It can be seen from the statistical data that archival research has been the most widely used method in empirical accounting research in China. There are 248 articles in the study of archives, accounting for $94.7 \%$ of the number of articles retrieved. In a further classification can be seen in the archives of the empirical analysis is the most frequently used method, a total of 149 articles in the empirical analysis, accounting for $56.9 \%$ of the total number of retrieved articles, the inspection is to assume that next use more, with this method uses 84 article, accounting for the $32.1 \%$ of the total number of retrieved articles. In addition to the research methods of other research methods the use of archives is very little, this is due to the particularity of accounting disciplines, using similar laboratory research methods in the empirical research in accounting is not suitable for.

\section{Classification and Statistics of Comprehensive Research Contents and Research Methods}

Statistical data from 2006 to 2016, accounting empirical research on classification statistics of different content research methods can be very obvious that the different methods of empirical research of accounting in our country its use is mainly empirical analysis and hypothesis testing. The accounting information, accounting standards, financial problems, cash flow and accounting policy choice and several aspects of this study using empirical analysis method than hypothesis testing method in two aspects, the rest is used on multiple hypothesis testing. [4] 


\section{The Differences between China and Western Countries in Empirical Accounting Research Methods}

\section{Differences in Research Content}

It can be seen that there are obvious differences between China and Western countries in the study of empirical accounting. By comparison, we can see that the content of Western empirical accounting research is more extensive than that of our country. In our country, the research content of empirical accounting is often limited to the research of financial accounting and auditing. This difference there are two main reasons, one is the positive accounting research to effective market hypothesis, capital asset pricing model, contingency theory and information asymmetry theory and some other economic theory as the research foundation, and the theory of economics in our previous education due to inadequate attention, in the depth and breadth of research on are far less than western countries. However, the development of capital market in our country is not yet mature, which is the key factor of accounting research environment in China and the west. At present, China's capital market is the final form, in many aspects is still immature, the lack of normative factors, so to some extent, affects the scope and results of accounting research. [5]

\section{Differences in Research Methods}

There are broad sense and narrow sense in the empirical research methods. In the narrow sense, the empirical research method refers to the archival research method, and the archival research includes three categories: observation analysis, empirical analysis and hypothesis testing. Through the above empirical accounting research in our country a series of literature analysis, China's accounting scholars in the empirical accounting research in this part, usually use the method of archival research, rarely in the use of other research methods, empirical research methods in foreign accounting on the use of a more comprehensive, in the course of the study also pay attention to comprehensive use for a variety of research methods, is a broad concept of empirical accounting research methods. The so-called broad sense of the concept of empirical accounting research, including archival research (observation and analysis, empirical analysis and hypothesis testing), case and field research, research, laboratory research in five areas. The reason for this difference is mainly due to the foreign academic atmosphere and research conditions are superior to our country. Foreign scholars in the empirical accounting research on the use of a wide range of research methods for the analysis of the practice is worth learning and reference. For example, in the treatment of laboratory research method point of view, Chinese scholars have been holding a social discipline cannot be through experiments to study the view like word according to the subject, but in the "contemporary" empirical research methods of accounting book "American accounting journal" published in 1995 to 1996 during the this paper focuses on the analysis of the statistical analysis, after the methods used in the article, the article found many research results are using this method to achieve the research laboratory. It can be seen from the results of the research of American scholars that the method of laboratory research can be used in the field of social science. Through this example to illustrate the application of the method in China should be based on the research of foreign scholars for reference, try to use more methods to study the empirical accounting research in China, enrich the empirical accounting.

\section{References}

[1] Lu Yonghua, Methodology of Accounting Research, China Financial Publishing House, Beijing, 2010.

[2] Yang Haifeng, Perspective and review of the application of empirical accounting research methods in China, Journal of financial accounting, 1(2004).

[3] Zhang Zhaomi, Be contemporary accounting research methods empirical, Dongbei University of Finance and Economics press, Dalian, 2001. 
[4] Li Huaizu, Methodology of management research, Xi'an Jiao Tong University press, Xi'an, 2010.

[5] Song Jing, Literature review on empirical research methods of Chinese accounting, Accounting Communication, 3(2011). 